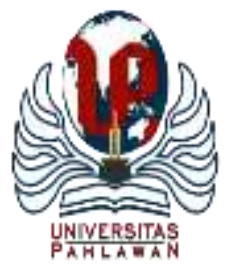

Edukatif : Jurnal Ilmu Pendidikan Volume 4 Nomor 1 Tahun 2022 Halm 1387 - 1395

EDUKATIF: JURNAL ILMU PENDIDIKAN

Research \& Learning in Education

https://edukatif.org/index.php/edukatif/index

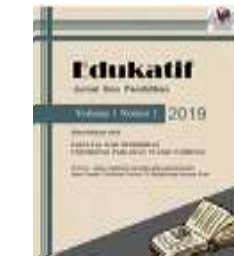

\title{
Nilai-Nilai QS (Emotional Quentient) dan SQ (Spritual Quentient) dalam Novel I'm Sarahza Karya Hanum Salsabiela Rais dan Rangga Almahendra
}

\author{
Maryam Nurlaila ${ }^{1 凶}$, Nazriani $^{2}$, Wa Ode Mirna ${ }^{3}$ \\ Pendidikan Bahasa Indonesia, Universitas Muhammadiyah Buton, Indonesia ${ }^{1,2,3}$ \\ E-mail : maryamnurlaila72@gmail.com ${ }^{1}, \underline{\text { Nazrianinani@gmail.com }}{ }^{2}, \underline{\text { Mirnaode@gmail.com }}{ }^{3}$
}

\begin{abstract}
Abstrak
Latar beakang penelitian ini adalah mendeskripsikan nilai-nilai EQ (Emotional Quention) dan SQ (Spritual Quentient) yang terdapat dalam novel I'm Sarahza karya Hanum Salsabiela Rais dan Rangga Almahendra. Penelitian ini bertujuan untuk menjabarkan nilai-nilai EQ (Emotional Quention) dan SQ (Spritual Quentient) yang terdapat dalam novel I'm Sarahza karya Hanum Salsabiela Rais dan Rangga Almahendra. Metode yang digunakan pada penelitian ini ialah metode deskripsi kualitatif memberikan pusat data terhadap data alamiah, data hubungan. Sedangkan jenis penelitian yang digunakan adalah jenis penelitian kepustakaan. Sumber data dalam penelitian ini adalah naskah novel I Am Sarahzah karya Hanum Salsabiela Rais dan Rangga Almahendra sebagai sumber data primer. Teknik pengumpulan data yang digunakan dalam penelitian ini adalah teknik/cara catat, karena data-datanya berupa teks. Hasil penelitian menganalisis nilai Emosional Quentient dalam novel I'm Sarahza karya Hanum Salsabiela Rais dan Rangga Almahendra yaitu 1) kemampuan mengenali emosi diri, 2) kemampuan memotivasi diri sendri, 3) kemampuan membina hubungan. Nilai Spritual Quentient alam novel I'm Sarahza karya Hanum Salsabiela Rais dan Rangga Almahendra yaitu 1) kejiwaan, 2) rohani, 3) batin.

Kata Kunci: Analisis, Nilai Emotional Quentient, Nilai Spiritual Quentient, novel I'm Sarahza.
\end{abstract}

\begin{abstract}
The background of this research is to describe the EQ (Emotional Quention) and SQ (Spritual Quentient). values contained in the novel I'm Sarahza by Hanum Salsabiela Rais and Rangga Almahendra. This study aims to describe the EQ (Emotional Quention) and SQ (Spritual Quentient) values contained in the novel I'm Sarahza by Hanum Salsabiela Rais and Rangga Almahendra. The method used in this study is a qualitative description method that provides a data center for natural data, relationship data. While the type of research used in this study is the type of library research. The data source in this study was the novel I Am Sarahzah by Hanum Salsabiela Rais and Rangga Almahendra as the primary data source. The data collection technique used in this research is the technique of recording, because the data is in the form of text. The results of the study analyzed the Emotional value of Quentient in the novel I'm Sarahza by Hanum Salsabiela Rais and Rangga Almahendra, namely 1) the ability to recognize one's emotions, 2) the ability to motivate oneself, 3) the ability to build relationships. The Spiritual Values of Quentient in the novel I'm Sarahza by Hanum Salsabiela Rais and Rangga Almahendra are 1) psychological, 2) spiritual, 3) inner.
\end{abstract}

Keywords: Analysis, Emotional Quentient Value, Spiritual Quentient Value, novel I'm Sarahza.

Copyright (c) 2022 Maryam Nurlaila, Nazriani, Wa Ode Mirna

$\triangle$ Corresponding author

Email : maryamnurlaila72@gmail.com

DOI : https://doi.org/10.31004/edukatif.v4i1.1988

ISSN 2656-8063 (Media Cetak)

ISSN 2656-8071 (Media Online) 
1388 Nilai - Nilai QS (Emotional Quentient) dan SQ (Spritual Quentient) dalam Novel I'm Sarahza Karya Hanum Salsabiela Rais dan Rangga Almahendra - Maryam Nurlaila, Nazriani, Wa Ode Mirna DOI: https://doi.org/10.31004/edukatif.v4i1.1988

\section{PENDAHULUAN}

Sastra Bahasa (Adabul-lughah) adalah kata-kata indah yang mengandung imajinasi yang cermat, pelukisan yang lembut, yang diwariskan atau dihasilkan oleh para penyair dan penulis, bertujuan untuk mendidik jiwa, menghaluskan rasa, dan budaya Bahasa (Ibnu Rawandhy Hula, 2016). Karya sastra adalah replika kehidupan nyata. Karya sastra adalah produk pikiran dan perasaan manusia (Manshur, 2012). Karya sastra adalah sebuah hasil ciptaan manusia yang menggambarkan kehidupan (baik gambaran nyata maupun tidak nyata) (Hermawan, dkk, 2019). Persoalan-persoalan yang diangkat oleh pengarang dalam karya sastra tidak lepas dari pengalaman nyata dalam kehidupan sehari-hari. Kehadiran tokoh dalam sebuah cerita sangatlah penting, tanpa ada tokoh dalam sebuah cerita, cerita tersebut tidak akan hidup (Bambang et al., 2021). Oleh karena itu, tokoh memberikan konstribusi yang sangat penting dalam karya sastra. Konflik dan tragedi yang digambarkan dalam karya sastra untuk memberikan kesadaran kepada pembaca bahwa ini bisa terjadi dalam kehidupan nyata dan dialami langsung oleh pembaca (Rifai, Achmad, 2020). Karya sastra juga berguna untuk pembaca sebagai media hiburan, tidak terkecuali prosa. Karya sastra coba menerjemahkan peristiwa kehidupan kedalam bahasa imajiner dengan maksud untuk memahami peristiwa sejarah menurut kadar pengetahuan pengarang, kemudian dapat dijadikan sebagai sarana bagi pengarang untuk menyampaikan pikiran, perasaan, dan tanggapan mengenai suatu peristiwa sejarah, serta karya sastra dapat berupa penciptaan kembali sebuah peristiwa sesuai dengan pengetahuan dan daya imajinasi pengarangnya (Risnawati et al., 2017).

Dunia kesastraan mengenal prosa sebagai salah satu genre sastra disamping genre-genre yang lain. Prosa dalam pengertian kesastraan juga disebut fiksi (fiction) (Zuliana, 2018). Prosa adalah karya sastra yang berbentuk tulisan bebas. Bersifat bebas artinya prosa tidak terikat dengan aturan-aturan tulisan seperti rima, diksi, irama, dan lain-lain. Makna kata dalam prosa sifatnya denotatif atau mengandung makna sebenarnya (Mataram et al., 2016). Jikapun terdapat kata-kata kiasan, mereka hanya menjadi ornamen di beberapa bagian untuk menekankan atau memperindah tulisan dalam prosa. Dalam Prosa terdapat Novel, novel merupakan bagian dari prosa baru yang banyak dipengaruhi oleh kebudayaan luar. (Totokpriyadi \& Seli, n.d.) berpendapat bahwa karya sastra dibuat sebagai "gejala-kejiwaan" yang di dalamnya terkandung fenomenafenomena kejiwaan yang menampak lewat perilaku tokoh-tokohnya, dengan demikian karya sastra (teks sastra) seperti novel pun dapat didekati dengan menggunakan pendekatan secara objekif atau struktural. Pendekatan objektif (struktural) adalah pendekatan karya sastra itu sendiri, terlepas dari sosial pengarang atau pembaca(Hastary, 2014).

Kompleksitas unsur-unsur yang terdapat dalam karya sastra, hal ini menuntut kepada kita berkaitan kajian sastra agar memiliki suatu kepekaan emosi atau perasaan dalam menikmati unsur-unsur keindahan cipta sastra. wawasan pengetahuan dan pengalaman yang luas terhadap masalah kehidupan dan kemanusiaan baik lewat penghayatan secara intensif-kontemplatif maupun dengan membaca berbagai literatur humanitas; pemahaman terhadap aspek kebahasaan; serta pemahaman terhadap unsur-unsur intrinsik cipta sastra yang berhubungan dengan telaah teori sastra (Setiyono, 2015).

Karya sastra yang diramu sedemikian rupa dari hasil persentuhan dengan lingkungan masyarakat menunjukkan bahwa karya sastra, khususnya novel, memuat realitas kehidupan manusia di dalamnya. (Studi et al., 2014) mengemukakan bahwa salah satu tujuan novel adalah menggambarkan kehidupan nyata, mendeskripsikan karakter-karakter, mensugestikan rancangan tindakan, dan memberikan penilaian terhadap motif-motif tindakan. Novel adalah karangan prosa yang lebih Panjang dari cerita pendek dan menceritakan seseorang dengan lebih mendalam dengan menggunakan Bahasa sehari-hari serta banyak membahas aspek kehidupan (Salam \& Fadhillah, 2019). Sehingga novel juga berfungsi sebagai sarana rekreatif yang dapat memberikan gambaran karakter pada masyarakat tertentu, baik kecerdasan intelektual (intelektual Quetient), kecerdasan emosi (Emotional Quetient) dan kecerdasan spritual (Spritual Quetient). 
1389 Nilai - Nilai QS (Emotional Quentient) dan SQ (Spritual Quentient) dalam Novel I'm Sarahza Karya Hanum Salsabiela Rais dan Rangga Almahendra - Maryam Nurlaila, Nazriani, Wa Ode Mirna DOI: https://doi.org/10.31004/edukatif.v4i1.1988

Kecerdasan emosi merupakan kemampuan lebih yang dimiliki seseorang dalam memotivasi diri sendiri (Thaib, 2013). Ketahanan dalam menghadapi frustasi, mengendalikan dorongan hati, mengatur suasana hati. (Manajemen et al., 2009) Kecerdasan Spritual menjadikan seseorang lebih bernilai dan dapat menyelesaikan masalah. Salah satu novel yang bercerita tentang nilai-nilai kecerdasan emosional dan spritual manusia tertentu dapat dilihat dalam novel I'm Sarahza karya Hanum Salsabiela Rais dan Rangga Almahendra. Kecerdasan emosional adalah kemampuan seseorang dalam mengenali perasaan diri sendiri, perasaan orang lain, memotivasi diri sendiri, dan kemampuan mengelola emosi (Ala, 2018). Kecerdasan intelektual memegang peranan penting bagi mahasiswa dalam memahami akuntansi, namun hal ini tidak akan berjalan dengan baik bila tidak diimbangi dengan kemampuan untuk mengelola emosi (EQ) sendiri ketika dihadapkan pada permasalahan, mahasiswa yang bersangkutan akan cepat frustasi (Parauba, 2014). Setiap individu menerapkan Intellectual, Emosional, dan Spiritual Quotient (IESQ), maka ketenangan dalam bekerja dan peningkatan kinerja akan diraih, baik dalam tempat kerja maupun dalam kehidupan sehari-hari (Iskandar et al., n.d.).

Novel ini menceritakan tentang seorang perempuan yang selama 11 tahun berjuang untuk mendapatkan seorang anak, dengan segala macam metode dan usaha dilakukan. Dalam novel ini dipenuhi oleh konflikkonflik emosional pada tokoh utama, dalam novel ini pengarang membuat kita seakan-akan merasakan tentang arti dari perjuangan mendapatkan seorang anak. Novel ini dipenuhi dengan emosional dari tokoh utama yang bernama Hanum dimana dengan penuh emosional, rasa putus asa, penuh tekanan karena dengan segala usaha untuk mendapatkan anak tidak berhasil, baik dari program bayi tabung, inseminasi, perpindahan induk telur tidak menghasilkan, sehingga tokoh utama yang bernama Hanum frustasi dan bahkan hampir menyerah. Dalam novel ini selain emosional yang ditunjukkan kepada pengarang terhadap tokoh utama, pengarang juga menceritakan tentang jiwa Spiritual tentang tokoh utama. (Wisnu Saputra et al., 2017) Dalam ruang lingkup Psikologis mengontrol emosional sangat di perlukan, karena mengingat kita sebagai makhluk sosial hidup selalu berinteraksi dengan orang lain, sehingga kita harus mampu mengimplementasikan diri kita terhadap diri sendiri, menahan emosi, bagaimana cara membina hubungan baik dengan orang sekitar serta tidak lupa dari jiwa Spiritual kita harus mengingat kepada sang maha pencipta terhadap suatu masalah yang kita hadapi.

Penelitian lain dalam Novel I'm Sarahza karya Hanum Salsabiela Rais dan Rangga Almahendra (Jenderal Penguatan Riset dan Pengembangan et al., 2021) judul "Analisis karakter tokoh utma dalam novel I'm Sarahza karya Hanum Salsabiela Rais dan Rangga Almahendra”. Hasil dalam penelitian tersebut yaitu, beberapa karakter yang berkesesuian dengan olah hati, olah pikir dan ada beberapa sifat yang dimiliki oleh beberpa tokoh utama. Adapun yang menjadi tujuan dalam penelitian ini adalah 1) Untuk mendeskripsikan nilai-nilai EQ (Emotional Quentient) dan SQ (Spritual Quentient) dalam Novel I'm Sarahza karya Hanum Salsabiela Rais dan Rangga Almahendra. 2) Untuk mendeksripsikan relevansi nilai-nilai EQ (Emotional Quentient) dan SQ (Spritual Quentient) dalam Novel I'm Sarahza karya Hanum Salsabiela Rais dan Rangga Almahendra pada pengajaran Sastra di sekolah.

Hasil penelitian ini dapat dimanfaatkan dalam pengajaran sastra di sekolah serta memperkaya penegetahuan siswa akan contoh nilai-nilai EQ (Emotional Quention) dan SQ (Spritual Quentient). Peranan dan pengembangan EQ dan SQ dalam dunia Pendidikan khususnya mempunyai arti yang sangat penting untuk mewujudkan individu yang berharkat dan bermanfaat baik secara fisik maupun psikis dengan kata lain mewujudkan peningkatan kualitas manusia seutuhnya. Penelitian ini memiliki perbedaan dengan penelitian sebelumnya yaitu menganalisis nilai-nilai EQ (Emotional Quentient) dan SQ (Spritual Quentient) dalam Novel I'm Sarahza karya Hanum Salsabiela Rais dan Rangga Almahendra sedangkan penelitian yang lain hanya menganalisis karakter tokoh utama dalam Novel I'm Sarahza karya Hanum Salsabiela Rais dan Rangga Almahendra. Atas dasar tersebut, peneliti memutuskan untuk melakukan penelitian dengan judul " nilai-nilai 
1390 Nilai - Nilai QS (Emotional Quentient) dan SQ (Spritual Quentient) dalam Novel I'm Sarahza Karya Hanum Salsabiela Rais dan Rangga Almahendra - Maryam Nurlaila, Nazriani, Wa Ode Mirna

DOI: https://doi.org/10.31004/edukatif.v4i1.1988

EQ (Emotional Quentient) dan SQ (Spritual Quentient) dalam Novel I'm Sarahza karya Hanum Salsabiela Rais dan Rangga Almahendra".

\section{METODE PENELITIAN}

Metode dalam penelitian ini adalah metode deskriptif. Metode ini digunakan karena sesuai dengan objek penelitian sekaligus sumber data yang berbentuk teks yaitu tindak tutur pada novel "I Am Sarahza" karya Hanum Salsabiela Rais dan Rangga Almahendra. Penelitian yang bersifar deskriptif berarti penelitian data terurai dalam bentuk kata-kata atau gambar-gambar bukan dalam bentuk angka-angka (Sarbaini, 2017). Bentuk penelitian ini menggunakan bentuk kualitatif. Bentuk ini tidak memaparkan bentuk angka-ankga perhitungan, tetapi menampilkan analisis data yang diperoleh. Alasan peneliti dalam menggunakan bentuk penelitian ini karena lebih sesuai dengan objek penelitian yang akan diteliti.

Adapun sumber data dalam penelitian ini berasal dari teks novel I'm Sarahza karya Hanum Salsabiela Rais dan Rangga Almahendra yang telah dibentuk buku berjudul I'm Sarahza karya Hanum Salsabiela Rais dan Rangga Almahendra. Teknik pengumpulan data dalam penelitian ini adalah studi dokumenter. Penulis menggunakan analisis tindak tutur pada novel I Am Sarahza karya Hanum Salsabiela Rais dan Rangga Almahendra. sebagai sumber data penelitian ini. Maka teknik studi dokumenter dilakukan dengan cara mengumpulkan data yang berhubungan dengan tindak tutur.

Alat dalam pengumpulan data penelitian ini adalah peneliti sendiri. Dalam hal ini peneliti sebagai instrumen utama. Kedudukan peneliti sebagai instrumen utama dalam penelitian ini yaitu sebagai perencana, pelaksanaan, pengumpulan data, analisis, penafsiran, dan pada akhirnya menjadi pelapor hasil penelitian. Selain peneliti sebagai instrumen utama, digunakan juga alat pengumpulan data lainnya berupa kartu data yang digunakan untuk mencatat data-data yang akan dianalisis. Tahapan dalam penelitian ini adalah 1) menentukan sumber penelitian yang akan dianalisis, 2) membaca novel I'm Sarahza karya Hanum Salsabiela Rais dan Rangga Almahendra untuk mendapatkan data nilai-nilai EQ (Emotional Quentient) dan SQ (Spritual Quentient), 3) menandai nilai-nilai EQ (Emotional Quentient) dan SQ (Spritual Quentient) yang terdapat dalam novel I'm Sarahza karya Hanum Salsabiela Rais dan Rangga Almahendra dan mencatatnya dlam tabel yang telah disiapkan, 4) menganalisis nilai-nilai EQ (Emotional Quentient) dan SQ (Spritual Quentient) yang terdapat dalam novel I'm Sarahza karya Hanum Salsabiela Rais dan Rangga Almahendra.

\section{HASIL DAN PEMBAHASAN PENELITIAN}

Berdasarkan hasil penelitian yang dilakukan penulis maka dapt ditemukan beberapa nilai EQ (Emotional Quentient) dan SQ (Spritual Quentient) yang terkandung dalam novel I'm Sarahza karya Hanum Salsabiela Rais dan Rangga Almahendra. Penulis rangkum menjadi tiga nilai Emotional Quentient, yaitu mengenali emosi diri, memotivasi diri sendiri, dan membina hubungan. Serta dalam Spritual Quentient penulis rangkup menjadi tiga nilai, yaitu kejiwaan, rohani dan batin.

\section{Nilai-nilai EQ (Emotional Quentient)}

\section{Kemampuan Mengenali Emosi Diri}

Sikap mengenali emosi diri menunjukan kemampuan untuk memantau perasaan dari waktu ke waktu. Mengelola emosi orang - orang buruk kemampuan dalam keterampilan ini akan terus-menerus bertarung melawan perasaan murung, sementara mereka yang pintar dapat bangkit kembali jauh lebih cepat dan kejatuhan dalam kehidupan penguasaan diri, yaitu kemampuan untuk menghadapi badai emosional. Hal tersebut dapat dilihat dari kutipan berikut;

"Aku kan udah bilang. Aku nggak mau ngarep macam-macam. Jadi jangan ngomong macam-macam. Cuma masuk angin biasa kok.” 
1391 Nilai - Nilai QS (Emotional Quentient) dan SQ (Spritual Quentient) dalam Novel I'm Sarahza Karya Hanum Salsabiela Rais dan Rangga Almahendra - Maryam Nurlaila, Nazriani, Wa Ode Mirna DOI: https://doi.org/10.31004/edukatif.v4i1.1988

Kutipan diatas menggambarkan tentang emosi pada tokoh Hanum kepada sang suami, dimana sang suami mengira dia dalam kondisi hamil dan mengharapkan lebih akan tetapi hal yang inginkan salah, Hanum hanya masuk angin biasa, bukan dalam kondisi hamil.

"Aku kan udah bilang. Aku nggak mau ngarep macem-macem. Jadi jangan ngomong macem-macem, Cuma masuk angin biasa kok."

"Mas! Aku nggak keguguran! Aku MENS mas! Aku... MENS.TRU.A.SI."

"Mas hadapilah! Tanda-tanda orang hamil hampir sama dengan orang mau haid. Memang hari ini sudah jatuh tempo siklus mensku! I am not even pregnant, Mas! We failed! Failed. Failed. Failed again!."

Kutipan di atas ini mengambarkan emosi diri pada tokoh Hanum dimana menunjukan sikap emosi pada tokoh utama yang bernama Hanum yang emosi saat suaminya Rangga mengira Hanum sedang dalam kondisi hamil diakibatkan keduanya sangat mengharapkan seorang anak, sehingga Hanum mengontrol emosinya ketika suaminya berpikiran yang tidak sesuai. Jika dilihat dari kutipan diatas mengambarkan emosi ,penguasaan diri yang ditahan oleh tokoh utama yang bernama Hanum.

2. Memotivasi diri sendiri.

Memotivasi diri yaitu orang-orang yang memiliki harapan tinggi, memiliki ciri-ciri tertentu, diantaranya adalah kemampuan memotivasi diri, merasa cukup banyak akal untuk menemukan cara meraih tujuan, tetap memiliki kepercayaan yang tinggi bahwa segala sesuatu akan beres ketika sedang menghadapi masa sulit dana mempunyai keberanian untuk memecahkan tugas yang sangat berat menjadi tugas kecil yang mudah ditangani. Hal tersebut dapat dilihat dari kutipan dibawah ini;

"Aku Rangga Almahendra, akan melakukan apa pun. Denger! Akan melakukan apapun usaha buah hati kita. Inget janji ini. Aku bersaksi sama yang di atas sana, Say !."

"Aku yakin, seorang calon manusia yang dituliskan di Lauhul Mahfuzh, tengah menanti ditempatkan dalam rahimmu. Aku hanya punya keyakinan yang harus kupelihara!.”

Kemampuan memotivasi diri sendiri,dimana tokoh Rangga memiliki harapan tinggi, percaya diri bisa memiliki anak atau suatu hari nanti anugerah itu tiba, istirnya bisa mengandung, berjanji akan melakukan usaha apapun menemani istrinya dalam keadaan apapun, serta memiliki kepercayaan tinggi bahwa suatu hari nanti ada calon manusia yang di tulis di Lauhul Mahfuzh yang akan ditempatkan di rahim istirnya. Selain kutipan diatas terhadap kemampuan memotivasi diri lainnya seperti pada kutipan berikut;

"Bismillah ya mas, kita hirup bau wangi parfum,bunga, wangi masakan, wangi kopi bareng-bareng. Tapi juga bau gosong, sampah, sampai bau keringat bareng-bareng di perjalanan hidup ini. Nggak boleh tutup hidung, ngak boleh !"

"Berkali-kali gagal dalam program hamil, bukan berarti kegagalan berikutnya lebih gampang dijalani."

"Mas, nanti kalau aku nggak bisa melek lagi, aku minta maaf yah selama ini belum bisa kasih kamu..."

Dari Kutipan diatas mengambarkan sikap atau kemampuan tokoh yang bernama Hanum memiliki harapan tinggi ingin memiliki anak, menyakinkan suaminya akan tetap bertahan, memiliki kepercayaan yang tinggi bahwa segala sesuatu akan beres ketika sedang menghadapi tahap sulit dalam hidup, cukup luwes dalam menghadapi untuk menemukan cara alternatif agar sasaran tetap tercapai serta Hanum mempunyai keberanian untu memecahkan mengenai masalah hidupnya.

\section{Membina Hubungan}

Membina hubungan merupakan keterampilan mengelola emosi orang lain. Orang-orang yang hebat akan keterampilannya ini akan sukses dalam bidang apapun yang mengandalkan pergaulan yang mulus dengan orang lain. Kemampuan sosial ini memungkinkan seseorang membentuk hubungan, menyakinkan dan mempengaruhi, membuat orang- orang merasa nyaman. Kemampuan membina hubungan dalam novel ini dapat dilihat dalam kutipan berikut;

"Kalau aku nggak gagal inseminasi, aku nggak bakal ngerasain nikmatnya jadi istri kamu. Ngepel, nyapu, masak, nyuci, dan semua kerjaan yang nggak satupun kukerjain di Jakarta dulu." 
1392 Nilai - Nilai QS (Emotional Quentient) dan SQ (Spritual Quentient) dalam Novel I'm Sarahza Karya Hanum Salsabiela Rais dan Rangga Almahendra - Maryam Nurlaila, Nazriani, Wa Ode Mirna DOI: https://doi.org/10.31004/edukatif.v4i1.1988

"Satu lagi, gagal inseminasi malah mengasah keromantisanmu sebagai suami. You nailed it!."

Dari kedua kutipan di atas mengambarkan tokoh Hanum mencoba membina hubungan dengan sang Suami, dimana ketika sang suami merasa kecewa terhadap kegagalan inseminasi istrinya dalam proses bayi tabung. Sehingga tokoh Hanum mencoba menyakinkan dan mempengaruhi suaminya dengan kata-kata yang terdapat dalam kutipan tersebut. Selain kutipan diatas terdapat juga kutipan lain yang mengambarkan tentang membina hubungan seperti pada kutipan berikut;

"Tau nggak Say. Setiap aku nemenin kamu diatas panggung buat Talkshow buku, aku selalu berdoa, moga-moga nggak ada yang jahil nanya tentang anak."

"Sampai aku tuh yah, bilang ke moderatornya, bisik-bisik, nanti kalau peserta tanyanya melenceng ,bukan tentang buku, nggak usah ditanggapin yah Mbak. Karena ini Forum buku bukan forum keluarga Hanum dan Rangga."

"Bahkan di beberapa Talkshow, aku minta pertanyaannya di pilih dulu, biar aku seleksi. Paling degdegan tuh kalau Talkshow di radio. Duh gimana cara nyeleksinya. Untungnya selama ini nggak ada yang bandel nanyain anak sih."

Dari ketiga kutipan diatas mengambarkan demi membina hubungan yang baik dengan sang istri, tokoh Rangga sampai melakukan hal seperti kutipan diatas, dia selalu merasa cemas ketika dalam acara para penonton menanyakan tentang anak, takunya istrinya akan merasa terganggu dan down, sehingga tokoh Rangga melakukan hal seperti menyeleksi semua pertanyaan, ini menandakan tokoh Rangga adanya kemampuan membina hubungan dengan orang lain terutama istrinya agar istrinya merasa aman dan nyaman.

\section{Nilai-nilai SQ (Spritual Quentient)}

\section{Kejiwaan}

Kejiwaan adalah tingkat kemampuan kecerdasan, sifat dan perilaku serta kepribadian secara emosi. Dalam ilmu Spritual Quentient manusia mengunakannya untuk lebih cerdas dalam beragama dan menhubungkannnya dengan makna esensial dibelakang agama. Kejiwaan dalam novel ini dapat dilihat dalam kutipan berikut;

"Tumbuhkan selalu semangat kami Allah! Peluk kami. Kami akan terus mecoba!",

"kabarku untukmu hari ini memang nggak baik, Say, tapi believe me, Allah lagi nulis suratan takdir yang baik untuk kita. Jangan buru-buru, jangan tergesa-gesa, nanti suratnya kurang indah. Yang jelas kita akan tetap bersatu."

Dari Kutipan diatas menggambarkan tentang kejiwaan terhadap tokoh Rangga dalam posisi yang penuh emosional, penuh tekanan, pasrah akan harapan yang di mimpikan belum terwujud, tetapi dengan kemampuan menahan emosi dan masih mengingat sang peciptanya, yakin bahwa Allah tidak akan mencoba umatnya di luar batas kemampuan umatnya. Selain kutipan diatas terdapat juga beberapa kutipan yang mengambarkan tentang kejiwaan dalam novel ini diantaranya sebagai berikut;

"Tau nggak Say. Setiap aku nemenin kamu diatas panggung buat Talkshow buku, aku selalu berdoa, moga-moga nggak ada yang jahil nanya tentang anak."

"Sampai aku tuh yah, bilang ke moderatornya, bisik-bisik, nanti kalau peserta tanyanya melenceng ,bukan tentang buku, nggak usah ditanggapin yah Mbak. Karena ini Forum buku bukan forum keluarga Hanum dan Rangga."

"Bahkan di beberapa Talkshow, aku minta pertanyaannya di pilih dulu, biar aku seleksi. Paling degdegan tuh kalau Talkshow di radio. Duh gimana cara nyeleksinya. Untungnya selama ini nggak ada yang bandel nanyain anak sih."

Dari ketiga kutipan diatas mengambarkan tentang perjuangan seorang suami, dimana Tokoh Rangga melakukan cara agar tidak menganggu kejiwaan istrinya saat menghadiri suatu acara, dengan cara memilah 
1393 Nilai - Nilai QS (Emotional Quentient) dan SQ (Spritual Quentient) dalam Novel I'm Sarahza Karya Hanum Salsabiela Rais dan Rangga Almahendra - Maryam Nurlaila, Nazriani, Wa Ode Mirna DOI: https://doi.org/10.31004/edukatif.v4i1.1988

semua pertanyaan yang berhubungan dengan anak, karena Rangga yakin pertanyaan yang berhubungan dengan anak akan menganggu pikiran, kejiwaan istrinya.

2. Rohani

Spritual Quentient akan membimbing manusia dalam merencanakan sesuatu yang menjadi tujuan hidupnya, cenderung mengisi lembaran hidup lebih bermakna dan bijak, memberi arah dan arti kehidupan kita tentang kepercayaan mengenai adanya kekuatan non fisik yang lebih besar dari pada kekuatan kita. Kemampauan Rohani dalam novel ini dapat dilihat dari kutipan dibawah ini, sebagai berikut;

"Kabarku untukmu hari ini memang nggak baik, Say, tapi believe me, Allah lagi nulis suratan takdir yang baik untuk kita. Jangan diburu-buru, jangan digesa-gesa, nanti suratnya kurang indah. Yang jelas kita akan tetap bersatu, Say. Tetap bersatu."

"Tumbuhkan selalu semangat kami Allah! Peluk kami. Kami akan terus mencoba!

Dari kutipan diatas mengambarkan sifat Spritual yang dinampakkan oleh tokoh Rangga, dimana tokoh Rangga percaya tentang kuasa oleh sang pencipta, terus semangat dan pantang menyerah untuk mendapat anak. Pada kutipan pertama mengambarkan bahwa selalu percaya tentang skenario yang Allah S.W.T rancang lebih indah dari manusia dan akan tiba tepat pada waktunya, sedangkan dari kutipan kedua tokoh Rangga mengeluarkan semua perasaanya dan berharap sang pencipta selalu berada disisinya dan terus mencoba.

"Say, Insya Allah kamu salah satu hamba Allah yang dilindungi. Kenapa? Karena kamu masih punya rasa takut. Ketika takut, ujung-ujungya Cuma mikir Allah kan? That's good. Lihat sekelilingmu."

Dari kutipan diatas menggambarkan tentang kemampuan Tokoh Utama bernama Rangga tentang jiwa kerohaniannya, dimana cenderung mengisi lembaran hidupnya tentang arti kehidupan dan kepercayaan mengenai adanya kekuatan yang lebih besar dari pada kekuatan manusia. Suatu kesadaran yang menghubungkan manusia dengan sang pencipta ataupun yang kita namakan sebagai sumber keberadaan kita.

3. Batin

Batin dalam SQ (Spritual Quentient) batin adalah konflik yang disebabkan oleh adanya gagasan atau keinginan yang bertentangan menguasai diri individu sehingga mempengaruhi tingkah laku. Biasanya dihadapi oleh orang yang memiliki banyak masalah pribadi tetapi tidak memperoleh pemecahannya. Gejala-gejala yang dapat terlihat yakni kekuatan-kekuatan yang tidak dapat diterangkan dan perasaanperasaan cemas sangat mempengaruhi kepribadian individu dan gangguan penyesuaian diri pada dunia sekitarnya. Kemampauan Batin dalam novel ini dapat dilihat dari kutipan dibawah ini, sebagai berikut;

"Tau nggak Say. Setiap aku nemenin kamu diatas panggung buat Talkshow buku, aku selalu berdoa, moga-moga nggak ada yang jahil nanya tentang anak."

"Sampai aku tuh yah, bilang ke moderatornya, bisik-bisik, nanti kalau peserta tanyanya melenceng ,bukan tentang buku, nggak usah ditanggapin yah Mbak. Karena ini Forum buku bukan forum keluarga Hanum dan Rangga."

"Bahkan di beberapa Talkshow, aku minta pertanyaannya di pilih dulu, biar aku seleksi. Paling degdegan tuh kalau Talkshow di radio. Duh gimana cara nyeleksinya. Untungnya selama ini nggak ada yang bandel nanyain anak sih."

Dari kutipan diatas mengambarkan tentang kemampuan batin yang di rasakan oleh Tokoh Rangga, tokoh Rangga memiliki perasaan- perasaan cemas terhadap situasi yang dihadapi beserta istrinya, dimana dalam kutipan tersebut tokoh Rangga mencoba melakukan hal-hal yang tidak membuat batin atau jiwa istrinya terganggu dengan lingkungan sekitar dan pertanyaan-pertanyaan yang membuat jiwa istrinya terguncang. 
1394 Nilai - Nilai QS (Emotional Quentient) dan SQ (Spritual Quentient) dalam Novel I'm Sarahza Karya Hanum Salsabiela Rais dan Rangga Almahendra - Maryam Nurlaila, Nazriani, Wa Ode Mirna DOI: https://doi.org/10.31004/edukatif.v4i1.1988

\section{KESIMPULAN}

Penjabaran nilai-nilai EQ (Emotional Quentient) dan SQ (Spritual Quentient) dalam novel I'm Sarahza karya Hanum Salsabiela Rais dan Rangga Almahendra berdasarkan hasil analisis terdiri dari enam kemampuan mengacu pada definisi menurut Salovey dan Mayer (1990:15) yaitu kemampuan mengenali emosi diri, memotivasi diri sendiri, membina hubungan, kejiwaan, rohani dan batin. Penggambaran nilai-nilai EQ (Emotional Quentient) dan SQ (Spritual Quentient) dalam novel I'm Sarahza karya Hanum Salsabiela Rais dan Rangga Almahendra dapat terlihat melalui sikap, perilaku dan tindakan pada tokoh dalam cerita yang memiliki tekad dan usaha yang lebih baik yang tergambar pada masing-masing tokoh.

\section{DAFTAR PUSTAKA}

Ala, H. M. (2018). Analisis Pengaruh Kecerdasan Intelektual, Kecerdasan Emosional Dan Kecerdasan Spiritual, Terhadap Etika Akuntansi. Jurnal Wahana, 21(1), 46-53.

Bambang, I., Pratiwi, W. D., \& Nurhasanah, E. (2021). Analisis Tindak Tutur Direktif Pada Novel LajangLajang Pejuang Karya Endik Koeswoyo Dan Pemanfaatannya Dalam Pembelajaran Teks Pidato Di Smp. Edukatif: Jurnal Ilmu Pendidikan, 3(6), 3769-3778. Https://Edukatif.Org/Index.Php/Edukatif/Index\%0aanalisis

Hastary, M. (2014). Makna Yang Tersirat Dalam Bahasa Puisi “Jangan Tanggung Jangan Kepalang” Karya Sutan Takdir Alisyahbana. Bina Bahasa, 17-26.

Hermawan, Dkk. (2019). Pemanfaatan Hasil Analisis Novel Seruni Karya Almas Sufeeya Sebagai Bahan Ajar Sastra Di Sma. Jurnal Bahasa, Sastra Indonesia Dan Pengajarannya, 12(1), 11-20.

Ibnu Rawandhy Hula. (2016). Kaidah Intrinsik Prosa Imajinatif Arab Dalam Ranah Kritik Sastra. Ajamiy: $\begin{array}{lllll}\text { Jurnal Bahasa Dan } & \text { Sastra } & \text { 117-130 }\end{array}$ Https://Doi.Org/Http://Dx.Doi.Org/10.31314/Ajamiy.5.1.117-130.2016

Iskandar, A., Yunus, M., \& Madjid, I. (N.D.). ... Emosional Dan Kecerdasan Spiritual Terhadap Kepemimpinan Transformasional Dan Dampaknya Terhadap Kinerja .... 29-31.

Jenderal Penguatan Riset Dan Pengembangan, D., Riset, K., Dan Pendidikan Tinggi Republik Indonesia, T., Fazalani, R., \& Qamarul Huda Badaruddin, U. (2021). Kredo 4 (2021) Kredo: Jurnal Ilmiah Bahasa Dan Sastra Terakreditasi Sinta 4 Berdasarkan Keputusan Analisis Karakter Tokoh Utama Dalam Novel I Am Sarahza Karya Hanum Salsabiela Rais \& Rangga Almahendra. 4(2). Https://Jurnal.Umk.Ac.Id/Index.Php/Kredo/Index

Manajemen, J., Sina, P. G., \& Noya, A. (2009). Pengaruh Kecerdasan Spiritual Terhadap. Pengaruh Kecerdasaan Spirtual Terhadap Pengelolaan Keuanagan Pribadi, 11(2), 171-188.

Manshur, F. M. (2012). Teori Sastra Marxis Dan Aplikasinya Pada Penelitian. Bahasa Dan Seni, 40 No. 1, $122-134$.

Mataram, U., Keguruan, F., Ilmu, D. A. N., Pendidikan, J., Dan, B., Studi, P., Bahasa, P., Indonesia, S., \& Daerah, D. A. N. (2016). Amuk, Kapak Karya Sutardji Calzoum Bachri O , Amuk, Kapak Karya Sutardji Calzoum Bachri.

Parauba, I. (2014). Pengaruh Kecerdasan Intelektual, Kecerdasan Emosional, Kecerdasan Spiritual, Dan Perilaku Belajar Terhadap Pemahaman Akuntansi Mahasiswa Fakultas Ekonomi Dan Bisnis Universitas Sam Ratulangi Manado. Going Concern: Jurnal Riset Akuntansi, 9(2), 53-67. Https://Doi.Org/10.32400/Gc.9.2.5059.2014

Rifai, Achmad, G. S. (2020). 済無no Title No Title No Title. Kekuatan Hukum Lembaga Jaminan Fidusia Sebagai Hak Kebendaan, 21(2).

Risnawati, R., Anshari, A., \& Abidin, A. (2017). Pertentangan Dan Kesadaran Kelas Dalam Novel Bumi 
1395 Nilai - Nilai QS (Emotional Quentient) dan SQ (Spritual Quentient) dalam Novel I'm Sarahza Karya Hanum Salsabiela Rais dan Rangga Almahendra - Maryam Nurlaila, Nazriani, Wa Ode Mirna DOI: https://doi.org/10.31004/edukatif.v4i1.1988

Manusia Karya Pramoedya Ananta Toer (Pendekatan Teori Marxis). Retorika: Jurnal Bahasa, Sastra, Dan Pengajarannya, 9(1), 68-79. Https://Doi.Org/10.26858/Retorika.V9i1.3795

Salam, D., \& Fadhillah, D. (2019). Aspek Psikologi Pada Novel Berjudul Assalamualaikum Beijing Karya Asma Nadia (Tinjauan Psikologi Sastra). Lingua Rima: Jurnal Pendidikan Bahasa Dan Sastra Indonesia, 6(2), 15. Https://Doi.Org/10.31000/Lgrm.V6i2.1613

Sarbaini, N. I. W. (2017). Nilai-Nilai Pendidikan Karakter Dalam Percakapan Pada Pertunjukan Mamanda (Character Education Values In Conversation Of Mamanda Show). Jurnal Bahasa, Sastra Dan Pembelajarannya, 4(2), 285. Https://Doi.Org/10.20527/Jbsp.V4i2.3702

Setiyono, J. (2015). Kajian Feminisme Dalam Cerpen Lelaki Ke-1000 Di Ranjangku Karya Emha Ainun Najib. Jurnal Pendidikan Edutama, 2(1).

Studi, P., Bahasa, P., Sastra, D. A. N., Keguruan, F., Ilmu, D. A. N., \& Purworejo, U. M. (2014). Novel Satin Merah Karya Brahmanto Anindito.

Thaib, E. N. (2013). Hubungan Antara Prestasi Belajar Dengan Kecerdasan Emosional. Jurnal Ilmiah Didaktika, Xiii(2), 384-399.

Totokpriyadi, A., \& Seli, S. (N.D.). Analisis Konflik Tokoh Dalam Novel Iam Sahraza Karya Diklasifikasikan Ke Dalam Sedangkan Psikologi Merujuk Kepada Srudi Ilmiah Tentang Prilaku Manusia Dan Proses Mental . Meskipun Berbeda, Keduanya Memiliki Titik Temu Atau Kesamaan, Yakni Keduanya Beran. $1-11$.

Wisnu Saputra, G., Aldy Rivai, M., Su, M., Lana Gust Wulandari, S., \& Rosiana Dewi, T. (2017). Pengaruh Teknologi Informasi Terhadap Kecerdasan (Intelektual, Spiritual, Emosional Dan Sosial) Studi Kasus: Anak-Anak. Journal.Uinjkt.Ac.Id, $\quad$ 10(2), 77-88 Http://Journal.Uinjkt.Ac.Id/Index.Php/Sisteminformasi/Article/View/7755

Zuliana, D. (2018). Analisis Semiotik Ada Surga Di Rumahmu. H.27. 